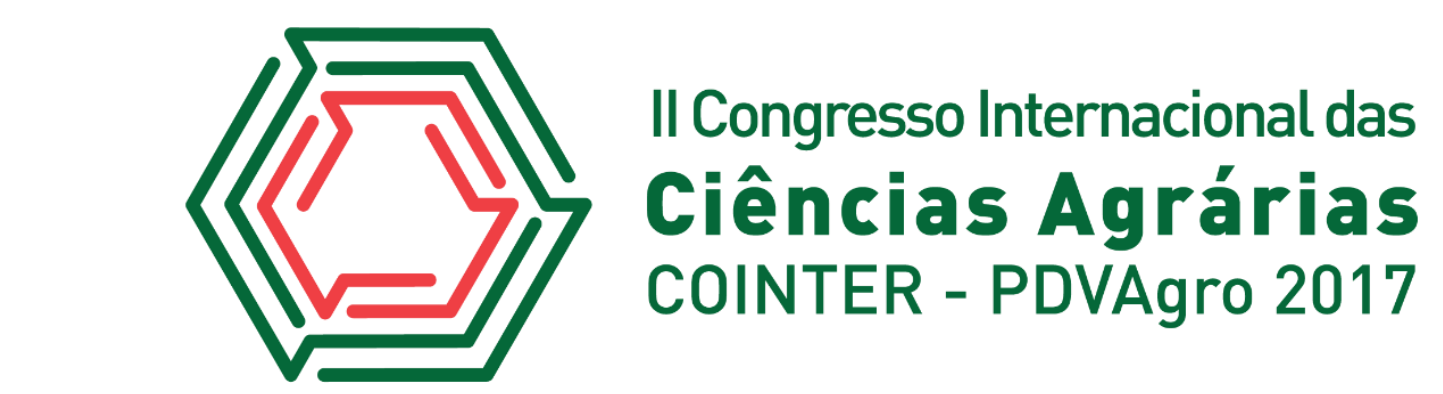

\title{
INFLUÊNCIA DA ADIÇÃO DA ERVA-SAL (Atriplex nummularia) NA QUALIDADE MICROBIOLÓGICA DA CARNE DE FRANGO
}

\author{
Apresentação: Pôster \\ Leandro Alves da Silva ${ }^{1}$; Marilia Celeste Tavares Fernandes ${ }^{2}$; Maria Carla da Silva \\ Campêlo $^{3}$; Lucas de Oliveira Soares Rebouças ${ }^{4 ;}$ Patrícia de Oliveira Lima ${ }^{5}$
}

\section{Introdução}

A carne de frango é a proteína animal mais consumida no país, atualmente. De acordo com pesquisa realizada pela Associação Brasileira de Proteína Animal, em 2015 ela estava presente em $100 \%$ dos lares brasileiros (ABPA, 2016). A produção de carne de frango é influenciada por diversos fatores que contribuem para o seu crescimento, dentre eles, destacam-se a qualidade da carne, o valor econômico atribuído ao mesmo em seu sistema de produção e a precocidade dos mesmos que proporciona um ciclo mais curto.

Tratar de qualidade microbiológica é saber se determinado produto está apto a ser consumido, garantindo segurança alimentar para o consumidor. Pesquisas têm sido realizadas com o uso de aditivos naturais, em busca de se obter um alimento livre de resíduos industriais que são maléficos ao ser humano e que provocam diversas doenças cardiovasculares, por exemplo, e que de certa forma tem sido questionado pelos órgãos competentes o uso indiscriminado desses aditivos na alimentação humana (CARMINATTI, 2015).

\section{Fundamentação Teórica}

O maior consumo da carne de frango aliado à mudança de hábito alimentar da população, faz com que haja a necessidade de aprimoramento nos processos de produção, ocasionando a substituição de produtos convencionais por industriais (FERREIRA, 2015). Desse modo, o uso de

\footnotetext{
${ }^{1}$ Zootecnia, Universidade Federal Rural do Semi-Árido (UFERSA), Email: leandrozootecnia@hotmail.com

2 Zootecnia, UFERSA, E-mail: marilia.tavares.cp@hotmail.com

${ }^{3}$ Pós- graduação em Ciência Animal, UFERSA, Email: carlacampelo2@hotmail.com

${ }^{4}$ Pós- graduação em Ciência Animal, UFERSA, Email: Iucaslosr@gmail.com

${ }^{5}$ Docente, UFERSA, Email: pattlima@ufersa.edu.br
} 
aditivos nos alimentos se torna cada vez mais necessário para garantir a integridade e aumentar o tempo de vida útil do produto (HONORATO et al., 2013). O uso de aditivos nos alimentos objetiva melhorar o valor nutricional, garantir a segurança microbiológica, aumentar a vida útil do alimento e melhorar as qualidades organolépticas (ANVISA, 2016; BNDES, 2014).

Mediante isso, o uso de aditivos naturais tem sido estudado com o intuito da substituição aos conservantes artificiais e a erva-sal tem despertado o interesse de alguns pesquisadores devido as suas características morfofisiológicas. Ela tem capacidade de tolerância a solos salinos e de acumular quantidades significativas de sais em seus tecidos (MOURA, 2013). Com isso, objetivouse avaliar a adição da erva-sal como conservante natural e seus efeitos nas características microbiológicas e na qualidade da carne frango.

\section{Metodologia}

O experimento foi desenvolvido na Universidade Federal Rural do Semi-Árido (UFERSA) e as amostras de carne de frango foram adquiridas em supermercados da cidade. Foram utilizados filés de peito, que foram pesados e separados em quatro grupos, cada um submetido a um tratamento: 0ES (carne de frango sem adição da erva sal), 1ES (carne de frango com 1\% de adição da erva-sal); 2,5ES (carne de frango com 2,5\% de adição da erva-sal); 5ES (carne de frango com adição de 5\% de erva-sal). Cada tratamento contendo aproximadamente $180 \mathrm{~g}$ de carne. As amostras foram acondicionadas em recipientes esterilizados, isolados com papel filme e armazenados sob temperatura de refrigeração $4^{\circ} \mathrm{C} \pm 1^{\circ}$.

As análises microbiológicas foram realizadas no Laboratório de Inspeção de Produtos de Origem Animal (LIPOA) da UFERSA. Foram realizadas no tempo de armazenamento zero, 1 dia após a inserção dos tratamentos e, subsequentemente, no $3^{\circ}$ e $6^{\circ}$ dias de armazenamento, refrigerado a $4 \pm 1^{\circ} \mathrm{C}$, sendo contabilizados os tempos subsequentes a partir do tempo zero. Após a diluição, as amostras foram submetidas às técnicas de contagem total de bactérias psicrotróficas e bactérias aeróbias mesófilas, utilizando a metodologia oficial brasileira para análises microbiológicas de alimentos (DOWNES \& ITO, 2001).

Os dados foram submetidos à análise de variância e teste de comparação de médias. Os efeitos dos diferentes tratamentos sobre cada variável foram comparados por meio do teste de Tukey, ao nível de 5\% de probabilidade, utilizando o SISVAR versão 5.6. 


\section{Resultados e Discussões}

Os resultados da analise microbiológica estão apresentados na Tabela 1. Todas as amostras apresentaram ausência de salmonella sp., sendo um resultado positivo como indicativo de segurança alimentar. A contagem das bactérias mesófilas e psicrotróficas é usada como indicador de qualidade microbiológica de um produto, sendo estes capazes de deteriorar o alimento. $\mathrm{O}$ uso da erva-sal na carne de frango apresentou resultados significativos $(\mathrm{p}<5 \%)$ para bactérias mesófilas nos dias 3 e 6 com valores acima de $6 \log \mathrm{UFC} / \mathrm{g}$, mostrando que não foi capaz de inibir o crescimento microbiano. Em relação a concentração não houveram diferenças significativas para esse atributo.

Os valores encontrados para os psicrotróficos se elevaram a partir do $3^{\circ}$ dia amostral, com valores acima de 6,4 logUFC/g, mostrando que também não inibiu o desenvolvimento microbiano.

Tabela 1-Contagem de bactérias psicrotróficas e mesófilas na carne de frango com diferentes concentrações de erva-sal.

\begin{tabular}{ccccccc}
\hline \multirow{2}{*}{$\begin{array}{c}\text { Dias de } \\
\text { armazenamento }\end{array}$} & \multirow{2}{*}{ Análises } & \multicolumn{4}{c}{ Concentrações de erva sal } & \multirow{2}{*}{ CV (\%) } \\
\cline { 3 - 6 } & & $0 \%$ & $1 \%$ & $2,50 \%$ & $5 \%$ & \\
\hline 0 & $3,60 \mathrm{Ba}$ & $3,46 \mathrm{Ba}$ & $3,58 \mathrm{Ba}$ & $3,99 \mathrm{Ba}$ & \\
1 & Mesófilos & $3,08 \mathrm{Ba}$ & $3,43 \mathrm{Ba}$ & $3,74 \mathrm{Ba}$ & $4,04 \mathrm{Ba}$ & \multirow{2}{*}{14} \\
3 & $\left(\log _{10} \mathrm{UFC} / \mathrm{g}\right)$ & $4,53 \mathrm{Bb}$ & $6,08 \mathrm{Aa}$ & $6,30 \mathrm{Aa}$ & $6,20 \mathrm{Aa}$ & \\
6 & & $6,30 \mathrm{Aa}$ & $6,40 \mathrm{Aa}$ & $6,40 \mathrm{Aa}$ & $6,40 \mathrm{Aa}$ & \\
0 & & $4,15 \mathrm{Ba}$ & $3,97 \mathrm{Ba}$ & $4,79 \mathrm{Ba}$ & $4,83 \mathrm{Ba}$ & \\
3 & Psicotróficos & $3,85 \mathrm{Bb}$ & $4,40 \mathrm{Bb}$ & $4,28 \mathrm{Bb}$ & $5,38 \mathrm{Aa}$ & \multirow{2}{*}{2,14} \\
6 & $\left(\log _{10}\right.$ UFC/g) & $6,40 \mathrm{Aa}$ & $6,40 \mathrm{Aa}$ & $6,40 \mathrm{Aa}$ & $6,40 \mathrm{Aa}$ & \\
\hline
\end{tabular}

${ }^{\mathrm{A}, \mathrm{B}}$ Letras maiúsculas distintas na coluna indicam diferença entre os dias de armazenamento pelo teste Tukey $5 \%$.

a, b, Letras minúsculas distintas na linha indicam diferença entre os tratamentos pelo teste Tukey $5 \%$

De acordo com a literatura, níveis de contaminação por mesófilos de 2 a $5 \operatorname{logUFC/g~em~}$ carnes podem indicar condições higiênicas adequadas no abate e contagens acima de $6 \operatorname{logUFC/g}$ podem significar condições inadequadas (GILL, 1998) e indicar inicio do processo de deterioração com produção de odor desagradável e comprometimento da vida de prateleira. Lopes et al., (2007) avaliaram a contaminação por microrganismos mesofilos em carcaças de frango, encontrando valores médios de 6,4 , semelhante a presente pesquisa. 


\section{Conclusões}

O uso da erva-sal, na forma e concentrações que foram utilizadas nesse experimento, não foi capaz de inibir o desenvolvimento microbiano.

\section{Referências}

ABPA, Associação Brasileira de Produção Animal. Produção de carne de frango totaliza 13,146 milhões de toneladas em 2015.Brasil,2016

ANVISA. Agência Nacional de Vigilância Sanitária. Informe Técnico n. 70, de 19 de janeiro de 2016. Esclarecimentos Sobre a Declaração de Alegações de Conteúdo Para Aditivos Alimentares na Rotulagem de Alimentos e Bebidas. In: Diário Oficial da União. Brasília,19 de janeiro, 2016

\section{BNDES. Potencial de Diversificação da Industria Química Brasileira,2014.}

CARMINATTI, R. Conheça o Sal Verde, primeiro sal de origem vegetal do Brasil. Página 3. Balneário Camboriú. 9 jun. 2015. Disponível em:

$<$ http://mobile.pagina3.com.br/saude/2015/jun/9/1/artigo-conheca-o-sal-verde-primeiro-sal-deorigem-vegetal-do-brasil>. Acesso em: 05 agosto 2017.

FERREIRA,F. S. Aditivos Alimentares e Suas Reações Adversas no Consumo Infantil. Revista da Universidade Vale do Rio Verde, Três Corações, v. 13, n. 1, p. 397-407, 2015

GILL, C.O. Microbiological contamination of meat during sloughter and butchering of cattle, sheep and pigs. In: DAVIES,A; BOARD,R.The microbiology of meat and poutry, London: Blackie Academic and Professional, p. 118-157, 1998.

HONORATO,T.C.; BATISTA,E.; NASCIMENTO,K.O.; PIRES,T. Aditivos alimentares: aplicações e toxicologia. Revista Verde (Mossoró-RN-Brasil), v.8, n.5, p. 01- 11(Edição Especial), 2013.

LOPES,M.; GALHARDO,J.A.; OLIVEIRA,J.T.; TAMARINI,R.; SANCHES,S.F.; MULLER,E.E. Pesquisa de salmonella spp. E microrganismos indicadores em carcaças de frango e água de tanques de pré-resfriamento em abatedouro de aves. Semina: Ciências Agrárias, Londrina,v.28, n.3, p.465$476,2007$.

MOURA, E.S.R. Cultivo de erva sal irrigada com rejeito salino sob variação da umidade do solo. Dissertação (mestrado em irrigação e drenagem), Curso de Agronomia, Centro de Ciências Agrárias,UFERSA, Mossoró,2013.

DOWNES, F. P. \& ITO, H. (2001). Compedium of methods for the microbiological examination os foods. 4 ed. Washington: American Public Health Association, 676. 